\title{
La Corte Internacional de Justicia $\left.{ }^{*}\right)$
}

\author{
Por el Señor Doctor JOSE LUIS BUSTAMANTE Y RIVERO (1)
}

\begin{abstract}
Señor Presidente del Consorcio de Abogados Católicos,
Señor Fresidente de la Sociedad Peruana de Derecho Internacional,

Señores Magistrados de la Corte Suprema,

Señores y colegas.
\end{abstract}

Tratóndose de un auditorio como el que me escucha, constituido principalmente por magistrados y abogados distinguidísimos, nada o muy poco de lo que en esta charla voy a exponer será materia desconocida para ellos. Se trata de cuestiones familiares a los estudiosos del Derecho Internacional, de normas contenidas en instrumentos públicos vigentes como la Carta de las Naciones Unidas y el Estatuto de la Corte de Justicia. He de limitarme a exponer, a modo de divulgación, una institución legal ya conocida; los detalles vivientes $y$ objetivos con arreglo a los cuales esa institución ha nacido y la manera como actúa y funciona en la realidad. La insinuación que para cumplir esta tarea me ha hecho el Consorcio de Abogados Católicos merece mi más cordial acogida y mi profundo reconocimiento.

En la vida contemporánea hay un fenómeno de sumo interés que palpamos todos los días: cierta disparidad de concepciones, cierta extraña discrepancia entre lo social y lo político. Lo social se diría una cosa universal, permanente, unánime; lo político es, en cambio, algo que varía según los países, algo en que se marcan divergencias, algo que suscita luchas y enconos. Como fondo común a lo social y lo político alienta un anhelo universal: el anhelo de paz. Pero mientras en el fenómeno social todos los pueblos unánimemente persiguen el mejoramiento de la vida hu-

(1). Ex-Presidente de la República del Perú. Juez de la Corte Internacional de Justicia de Ia Haya.

(*) Conferencia dictada en la Facultad de Derecho de la Universidad Católica el 7 de agosto de 1963, bajo los auspicios del Consorcio de Abogados Católicos. 
mana en sus atributos superiores, en el campo poítico la manera como los Gobiernos de los Estados entienden la posibilidad de ese mejoramiento es diferente en cada caso; y esto suscita discrepancias de Estado a Estado. Tales divergencias políticas acerca de los procedimientos para alcanzar el mejoramiento social, traen los conflictos y las guerras. Y entonces surge el anhelo de obtener una política uniforme que logre pacíficamente el mejoramiento social. En este anhelo de paz se ha cifrado la esperanza de los pueblos en todas las épocas y a este anhelo de paz han servido diferentes recuros o medios ideados por los hombres, por los tratadistas y por los políticos para lograr la unificación de pareceres y la eliminación de dificultades entre los diversos Estados a fin de orillar los conflictos bélicos. Esos recursos han sido gradualmente ensayados a través de una sucesión de épocas; en un principio se pensó simplemente en los arreglos bilaterales, y así surgieron los tratados. Más tarde, cuando surgió la idea de una organización internacional que presidiera los destinos del mundo organizado e introdujera en él normas obligatorias para todos, surgieron otros medios pacificadores además de los tratados y vino el ensayo de la conciliación bajo los auspicios de otros Estados; $y$ vino el ensayo de las mediaciones y vino el ensayo del arbitraje, primer asomo internacional de la administración de justicia entre Naciones.

No es objeto de esta charla establecer la historia del arbitraje ni tampoco enunciar sus ventajas y sus inconvenientes. Lo que puedo decirles sintéticamente es que la justicia arbitral, flexible desde ciertos puntos de vista, tenía también inconvenientes graves. Digo que la justicia arbitral era flexible porque había arbitrajes de jure y arbitrajes de simple buena fe; no siempre se exigía que el juez-órbitro resolviera el caso que se le sometía con arreglo a las normas del derecho, era posible que lo resolviera con arreglo a las normas de la simple equidad, dentro de un criterio de buena fe; pero en la justicia arbitral la designación de los árbitros tenía sus inconvenientes, no siempre se escogía árbitros adecuados $y$ cuando el carácter de árbitro recaía en un Estado, no siempre se tenía suficiente confianza en la imparcialidad de ese Estado que podía tener vinculaciones más o menos cercanas con una de las partes en litigio y no con la otra. Entonces se fue perfeccionando la idea de una justicia internacional que evitara conflictos, pero dentro de un concepto ya más vasto, cuando una institución de carácter internacional dentro de la cual la dispensación de la justicia se hiciera por elementos ajenos a toda influencia política y $\alpha$ toda influencia estatal, por elementos que centraran su empeño sólo en el concepto de justicia, con prescindencia de los intereses locales o particulares que se ventilaran en cada caso. Y así nació la idea de la actual justicia internacional que no es una justicia arbitral porque en ella la designación de juez no se hace para cada caso, sino que está preestablecida y es una designación que emana de un acuerdo electivo que podría decirse mundial porque la elección depende de la organización mundial oficial, que en. nuestros días se llama la Organización de las Naciones Unidas. Este podía ser el esquema del origen de la Corte de Justicia Internacional.

Como he dicho al principio de mi charla, casi parece ocioso reiterar algunos detalles que están escritos en la Carta de las Naciones Unidas y 
en los Estatutos de la Corte y que explican perfectamente la estructura y el funcionamiento de este Tribunal. Todos los señores Abogados aquí presentes conocen esos instrumentos internacionales y sería inútil entrar en detalle sobre su letra; pero tiene cierto interés divulgar los detalles de esta clase de instituciones para ver cómo viven, cómo se traduce en la práctica viviente la aplicación de la letra de los instrumentos internacionales creadores de la Institución. Esto es lo que yo me propongo hacer en esta charla, explicando a mis oyentes, primero cómo se ha estructurado la Corte Internacional y luego cómo funciona $y$ con arreglo a que principios se dictan sus decisiones.

La Corte Internacional de Justicia tiene en el mundo actual un antecedente. Puede decirse que la concepción de una justicia internacional vino a plasmarse ya en forma obligatoria, contractual y perfecta, a raíz de la Primera Guerra Mundial. Cuando entre los años 1918 y 1919 se organizaba la Sociedad de Naciones, y como un aditamento necesario del Pacto de la Liga de Naciones o Pacto de Versalles, se consignó la existencia de un Tribunal permanente que dispensara justicia entre los Estados miembros de esa Sociedad de Naciones. Y así nació la Corte Permanente de Justicia Internacional. Desgraciadamente esa Corte tuvo una vida corta. Hacia el año 1939 surgió la Segunda Guerra Mundial; hubo un obligado receso de la Corte Permanente por causa de esta guerra y ya desde antes de su estallido el funcionamiento de la Corte había sufrido grandemente en su normalidad por diferencias surgidas entre los Estados que abandonaban el camino de la justicia distribuida desde un Tribunal para enredarse en disputas directas y políticas. Sobrevenida la Segunda Guerra, la paralización de la justicia internacional duró tanto como aquella. Terminada la contienda hacia el año 45, se celebró la Conferencia de San Francisco, en la cual se redactaron las bases de la que había de ser luego la Carta de las Naciones Unidas y dentro de esa Carta se reiteró el mismo principio, la misma estipulación que ya contenía el Pacto de Versalles: fue establecida una Corte Internacional de Justicia que distribuyera la justicia entre los Estados Miembros de la nueva entidad, a la que se dió el nombre de Organización de las Naciones Unidas.

Vamos a examinar cuales son las características de esta nueva Corte que por lo demás se asemeja en mucho a la primitiva Corte Permanente, sin otras modificaciones que las exigidas por la nueva etapa recorrida por la comunidad internacional, por los nuevos adelantos que en materia de Derecho se había señalado y por las nuevas necesidades derivadas de la nueva forma de relaciones internacionales.

La estructura de la Corte Internacional de Justicia puede sintetizarse de este modo: se trata de un Tribunal constituido por 15 miembros, que naturalmente salen de los países que integran la Organización de las Naciones Unidas. Pero son 15 miembros respecto de los cuales la Carta de Nacione:s Unidas y el Estatuto de la Corte que es Ley Internacional no quiere que sean representantes de los países de donde emanan; hay cierto sentido de anacionalidad en el concepto de miembro de la Corte; los jueces de la Corte Internacional tienen que olvidarse en el acto de juzgar de su origen nacional y tienen que pensar simplemente en que son ciudadanos 
del mundo e instrumentos de la justicia. Este concepto, perfectamente señalado en la letra de la Carta y del Estatuto, es de suma importancia porque tiende a marcar de una manera enérgica la obligación del magistrado internacional de no acoger intereses particulares en la expedición de sus fallos y recordar que en ese momento es sólo instrumento de la comunidad de naciones deseosas de administrar una justicia esencial, sin la influencia de intereses nacionales determinados. La forma como se nombra a los Jueces de la Corte Internacional no hace sino reiterar este concepto de imparcialidad absoluta de que acabo de hablar. Los jueces de la Corte Internacional son elegidos por dos organismos de Naciones Unidas: por un lado, el Consejo de Seguridad y por otro, la Asamblea General. Son elegidos a propuesta de terceros organismos que aumentan todavía el carócter de imparcialidad en la designación de las cantidaturas. Esos terceros organismos son los que llamamos Grupos Nacionales de Juristas, lo cual exige una ligera digresión. Uds. saben perfectamente que desde antes de la organización de los tribunales permanentes de justicia internacional existía la Corte Internacional de Arbitraje, en la época del auge del sistema arbitral. Esa Corte se constituía por magistrados eventuales, entresacados de miembros del foro de diferentes países, seleccionados de la manera más severa. Los miembros del foro de cada Estado que podían ser en cada caso llamados a arbitrar en una causa, una vez designados conforme a normas que no es del caso citar ahora, constituían lo que se llama el Grupo Nacional. Estos miembros del grupo nacional de arbitraje de cada Estado son los que cuando se produce una vacante en la Corte Internacional están llamados a proponer a Naciones Unidas los nombres de un cierto número de juristas que estiman ellos dignos de figurar como candidatos para la Corte Internacional. El Grupo Nacional de juristas que propone estas candidaturas puede escoger miembros del foro o de la magistratura nacional, pero también puede escogerlos de entre los más destacados juristas extranjeros. Estas propuestas de los grupos nacionales de arbitraje de cada Estado son llevadas a la Secretaría General de Naciones Unidas y entonces la Secretaría General las pone en conocimiento simultáneamente del Consejo de Seguridad y de la Asamblea General. De estas propuestas eligen la Asamblea General y el Consejo de Seguridad los nom. bres de los que han de ser definitivamente nombrados jueces de la Corte Internacional. De este modo se obtiene una depuración máxima en la desigńación de jueces, porque los proponentes son también juristas de todo el mundo prácticamente y la proposición pasa bajo el tamiz de dos órganos de Naciones Unidas que recogen previamente informaciones sobre los antecedentes de los propuestos. Hay algo más, la elección de jueces se hace, no por países sino por grupos geográficos de Estados pertenecientes a diversos sistemas jurídicos. Para los efectos de la elección de miembros de la Corte Internacional, el mundo se divide en regiones geográficas, diríamos por ejemplo la América del Norte o Anglosajona, la América Latina del Sur, la Europa Occidental, la Europa Oriental, el Africa, el Asia, la Oceanía; $Y$ entonces de cada una de estas regiones geográficas se entresaca uno, o dos, o más juristas para que formen un conjunto hasta de quince juristas. Estos son los quince miembros que constituyen la Corte 
Internacional de Justicia, con sede en la ciudad de La Haya.

$\mathrm{El}$ período por el cual son elegidos los jueces es de nueve años; pero la renovación de la Corte se hace por tercios, es decir que cada tres años la Organización de Naciones Unidas elige cinco jueces. Esos cinco jueces nuevos vienen a inyectar conceptos nuevos, ideas nuevas, jurisprudencia nueva tal vez, en el seno de una Corte que conserva diez jueces ya expe. rimentados, ya avezados a la administración de justicia internacional por una próctica anterior. De ese modo se trata de conciliar la fuerza, el poder y el valor de la tradición jurídica con la introducción de elementos que traigan las nuevas auras del Derecho recogidas de los foros nacionales o del examen objetivo de la vida internacional.

El quorum para las reuniones de Sala Plena del Tribunal Internacional es de 9 miembros. En ciertos casos se exige un número de once. Pueden también formarse salas de tres miembros para asuntos de menor importancia.

Quienes pueden acudir al juzgamiento de este Tribunal Internacional? Desde luego todos los Estados Miembros de Naciones Unidas tienen derecho de llevar sus litigios o controversias a la Corte Internacional; pero también los Estados no miembros pueden hacerlo, aunque en este caso hay un procedimiento previo, una especie de tamiz que exige la Carta y que consiste en la proposición del Estado no miembro al Consejo de Seguridad para invocar jurisdicción de la Corte en un problema surgido con un tercer Estado. El Consejo de Seguridad, en la estructura de Naciones Unidas, viene a representar el poder moral y de influencia de las grandes potencias; el organismo de control en cuyas manos está en muchas ocasiones la decisión de la guerra o la paz, es decir, los más altos intereses del mundo. La Carta ha querido que sea este Organismo el que decida si un juicio en el que es parte un Estado no miembro puede ser sometido a la jurisdicción de la Corte Internacional.

Cuáles son las materias que pueden ser llevadas a la Corte Internacional?, Sobre qué han de versar los litigios que pueden ser ventilados ante ese Tribunal? EI Estatuto de la Corte que, repito, es una Ley Internacional aprobada por las Naciones Unidas a la vez que la Carta, establece concretamente cuáles son los casos o los puntos sobre los cuales deben versar los litigios que se lleven a la Corte. Se puede ventilar en la Corte cualquier duda sobre un punto de Derecho Internacional; y también, y eso de una manera primordial, la interpretación de los tratados internacionales $y$ sus infracciones.

Qué es lo que generalmente genera las controversias? Por lo regular las controversias internacionales se suscitan por razón de la interpretación de tratados. En estos casos se acude al juez para que interprete cual es el verdadero sentido del tratado. Pero, además, la Corte Internacional puede juzgar sobre hechos ocurridos en la vida de relación de dos Estados, hechos que en concepto de uno de esos dos Estados impliquen infracción de un tratado o de un derecho. $Y$, por último, se puede también llevar $a$ la Corte Internacional ciertos casos en los cuales, establecida la violación de un Tratado, exija un Estado de otro el pago de indemnización de los perjuicios ocasionados por la infracción del Tratado. Esos son los casos 
que según la Carta de Naciones Unidas y según el Estatuto de la Corte dan lugar a competencia de la Corte para dirimir los diferendos entre Estados.

Hay dos cuestiones interesantes que aclarar a este respecto. En primer lugar, son sólo los Estados los que pueden acudir a la Corte Internacional? Así es, en efecto, pero hay ocasiones en que, a raiz de controversias sobre intereses privados $\circ$ de particulares, el Derecho Internacional abre la posibilidad de que la Corte Internacional asuma jurisdicción. Este caso se produce cuando un Estado asume la protección de sus nacionales que son víctimas de infracciones legales, abusos o discriminaciones en país extranjero. Entonces el Estado hace suya la causa de sus nacionales, y, sea por la vía diplomática, sea mediante el recurso a la Corte Internacional, demanda al Estado responsable el restablecimiento del derecho. Tenemos precisamente en este momento en la Corte Internacional una causa de este género, que originalmente es de Derecho Privado, paro que se ha convertido en una causa de Derecho Público sometido a la Corte. Se trata del caso de la Barcelona Traction, Light and Power Ltd., compañía de electricidad en Cataluña, España. En esta compañía que originalmente es canadiense existen intereses de accionistas belgas, que objetaron como ilegales ciertos procedimientos del Directorio, y entonces formularon reclamaciones primero administrativas ante la misma compañía, y luego reclamaciones ante el Poder Judicial; pero llegó un momento en que por diversas circunstancias que no es del caso mencionar ios accionistas belgas acudieron a su Gobierno aduciendo que se habian producido irregularidades en los trámites judiciales que afectaban gravemente sus intereses y pidieron el patrocinio del Gobierno Belga para que ejercitara su defensa en la vía internacional. El Gobierno Belga acogió esta petición y formuló representaciones ante el Gobierno Español pidiéndole que orillara estas dificultades. No habiéndose llegado a un acuerdo, el Estado Belga ha demandado a España ante la Corte de La Haya.

El otro punto primordial acerca del cual quiero llamar la atención del auditorio es el relativo a la calidad de la jurisdicción ejercida por la Corte Internacional. La Corte Internacional de Justicia no tiene jurisdicción obligatoria para los miembros de Naciones Unidas. Esa jurisdicción es voluntaria. En el Estatuto de la Corte Internacional, que forma parte de la Carta de Naciones Unidas, existe artículo expreso que establece la voluntariedad por parte de cada Estado miembro para asociarse o no al conjunto de Estados que reconocen la jurisdicción de la Corte Internacional. Este es el que se llama el artículo opcional o cláusula facultativa del Estatuto de la Corte. Desde luego, desde el punto de vista de los principios, lo deseable sería que la jurisdicción de la Corte fuere obligatoria, porque de ese modo la contextura de la organización internacional mundial sería casi perfecta, en el sentido de que casi no habría posibilidad de que surgieran conflictos, porque surgido un conflicto no susceptible de ser orillado mediante los recursos normales de la conciliación, de la mediación, o del arbitraje, la organización internacional podría imponer a los Estados litigantes el sometimiento de ese conflicto a la Corte, y por consiguiente no habría posibilidad de un conflicto armado. Pero, desgraciadamente, en el 
camino de la perfección de las instituciones internacionales, no hemos llegado a ese grado porque se cruza un concepto que aunque bastante recortado ya, tiene todavía mucha fuerza en el mundo internacional: el concepto de la soberanía nacional. Al estructurar la Carta de Naciones Unidas se estimó que no se podía imponer obligatoriamente a todos los Estados la aceptación de la jurisdicción de la Corte, teniendo en cuenta en que hay ciertos litigios en que la materia litigiosa es tan sustancial, tan delicada, tan fundamental, que el Estado que tiene el litigio no puede someter a la decisión de un tercero materias o cosas que estima del resorte de su propia soberania y nada más que de ella, y entonces existe el temor de parte de los Estados de que pudiera entregarse a la decisión de un tercero, de un tribunal, un asunto en el que vive y palpita el interés fundamental del propio país. Entonces se ha llegado a una transacción en la Carta de Naciones Unidas y en el Estatuto, y la transacción es esta: se crea el organismo: al Tribunal Internacional, se le otorgan los máximos atributos de respeto $y$ de suficiencia, pero se deja a los Estados miembros la libertad de aceptar o no la jurisdicción de la Corte. Esa libertad se traduce de este modo: un Estado en cualquier momento puede presentar al Secretario General de Naciones Unidas una solicitud expresando que se adhiere a la cicausula facultativa $y$ por consiguiente reconoce como capaz de juzgar sus propios litigios a la Corte Internacional. Desde ese momento ese Estado está en la obligación, en primer lugar, de aceptar la jurisdicción y la intervención de la Corte si es demandado por otro Estado, y, en segundo lugar, está en la obligación de acatar el fallo que la Corte expida en ese asunto. Resulta, pues, que una de las características de la actual Corte Internacional es la voluntariedad de la jurisdicción. Naturalmente este factor disminuye la amplitud del radio de acción de la Corte en la vida práctica, porque sólo son llevados a la decisión judicial de la Corte aquallos asuntos en los que ha habido acuerdo previo de las partes para someter el asunto $\alpha$ esa competencia.

Establecida así la estructura de la Corte Internacional de Justicia, cabe hacer ahora una ligera reseña de cuál es el procedimiento, es decir como funciona la Corte Internacional. Lo primero que he de advertir es que, en general, la Corte funciona en Sala Plena en todos los asuntos graves, es decir con sus quince miembros, siendo el quorum mínimo de once. Sin embargo el Estatuto permite que, en ciertos asuntos de menos interés, de menor importancia, o de mayor facilidad, pueden formarse Salas de tres miembros, en los cuales el Tribunal delega sus facultades, de manera que la resolución o el fallo que emitiera en un caso dado una Sala de tres miembros tiene la misma fuerza y los mismos atributos que si la hubiera emitido un Tribunal en pleno. No sólo en asuntos ligeros puede intervenir una Sala de tres. Por acuerdo de las partes puede también darse el caso que los litigantes acepten constituir una Sala de tres o una Sala de cinco miembros y entonces, por acuerdo de partes, la Corte en pleno delega en esa Sala la función del juzgamiento.

El procedimiento se inicia por escrito. Hay dos etapas en el procedimiento de la Corte: la etapa escrita y luego la etapa oral. La etapa escrita comienza por lo que llamamos la "requéte", es decir la síntesis de 
la demanda. El Estado litigante presenta en un principio sólo una síntesis de la que va a ser su demanda y este documento se hace conocer a la otra parte, al otro Estado, para el efecto de que éste tome conocimiento de la acción instaurada. Cumplido este trámite previo, el Presidente pide a la parte demandante que presente la demanda en forma, o "memoria". La "memoria" es un documento extenso, en que está formulada la demanda con toda amplitud, y en donde el Estado demandante está obligado a expresar con toda claridad cuál es la materia de la demanda, cuál es el diferendo o punto litigioso cuya definición se pide a la Corte y también cuáles son las pruebas que el Estado demandante ofrece a fin de acreditarlo. De este documento que, por lo general, está ya desde el principio acompñado de anexos escritos porque la prueba instrumental se presenta generalmente con la memoria, se corre traslado al Estado demandado, y entonces puede suceder una de dos cosas: o dicho Estado formula excepciones dilatorias para impedir que se juzgue sobre el fondo del asunto, o el Estado demandado acepta la jurisdicción llanamente y contesta la demanda rebatiendo los argumentos sustanciales del demandante. Cuando se presentan excepciones, la más frecuente es la de incompetencia, esto es, aquella por la cual se alega que la Corte no está capacitada para asumir jurisdicción en el asunto, sea porque el Estado demandado no se adhirió a la claúsula facultativa o porque en los tratados que invoca el Estado demandante no está claro el sometimiento a la Corte, o ha sobrevenido caducidad. Alegada una excepción dilatoria, se corre traslado al demandante, quien expone sus razones en favor de la jurisdicción y entonces la Corte se reune para resolver, no sobre el fondo del litigio, sino sólo sobre excepciones planteadas.

En el caso de que no haya excepciones sino que el demandado proceda ya a contradecir la memoria en cuanto al fondo del asunto, el demandado presenta lo que se llama la "contra-memoria" en la cual se incluye también las pruebas documentales que quiera ofrecer el demandado o puede insertarse el ofrecimiento de pruebas testificales 0 de pruebas periciales que habrán de actuarse en la audiencia pública. En esta materia hay una perfecta analogía entre la naturaleza de las pruebas que pueden presentarse en el orden internacional y las que de ordinario se actúan en los foros nacionales: prueba de testigos, prueba de peritos, prueba instrumental, etc.

Manteniendo una costumbre del procedimiento nacional antiguo, todavía tenemos nosotros en la Corte Internacional los trámites de réplica y dúplica. Después de presentada la "memoria" y "contra-memoria", se corre traslado respectivamente a cada parte. El demandante formula su réplica combatiendo lo que haya dicho la parte en la "contra-memoria" y el demandado formula su dúplica refutando lo que se ha dicho en la réplica. De este modo se forma un proceso escrito, por lo regular voluminoso, y así termina el procedimiento escrito. Entonces comienza la etapa oral.

El Presidente de la Corte señala fecha para las audiencias públicas Y éstas se realizan de una manera semejante a las audiencias de los tribunales correccionales en el orden penal. Se reune el Tribunal en pleno (a menos que haya habido acuerdo para admitir Sala de tres o de cinco) 
y entonces acuden los agentes o apoderados de los Estados litigantes, acompañados de los Abogados defensores de los respectivos Estados. Naiuralmente dentro de la tradición de la Corte Internacional los Estados suelen escoger como abogados en sus causas a juristas notables, por lo regular profesones de Universidades o Procuradores nacionales de los diferentes Estados. El número de Abogados es libre; pueden por cada parte actuar uno, dos, tres, o más, porque hay ocasiones en que así lo requiere la complejidad del asunto. Hay causas en que se ventilan cuestiones de Derecho Político, de Derecho Internacional Público, de Derecho Internacional Frivado, de Derecho Comercial o Administrativo, y es frecuente entonces que las partes lleven abogados especializados en cada rama.

Una vez terminadas las exposiciones breves que presentan los dos Agentes, personeros o representantes de los Estados, comienzan las exposiciones de los Abogados y la actuación de las pruebas. No es frecuente la actuación de pruebas de peritos o de testigos, pero se dan casos. Hay casos también en que se ofrece la prueba de inspección ocular y entonces la Corte designa una Comisión de miembros suyos para que vavan al lugar de la inspección a fin de comprobar los hechos de visu, sentando, por supuesto, las actas correspondientes. Las exposiciones o alegatos de los abogados de cada una de las partes no tienen límites de tiempo y por cierto suelen ser piezas magistrales de oratoria forense en cuanto a solidez, argumentación y doctrina; de tal manera que por lo regular concurren a las audiencias estudiantes de Derecho.

Terminadas las audiencias, se cierra la etapa pública del juicio y comienza la etapa interna, lo que se llama en la jerga de la Corte la "cámara secreta". Se abren las deliberaciones reservadas de los jueces en mesa redonda, y allí se agota exhaustivamente cada materia tratada.

Lo primero que se hace es cambiar ideas, muy brevemente, sobre los sucesos culminontes de la audiencia que puedan tener alguna influencia fundamental en el fallo final. Luego se pasa a la presentación de notas escritas por cada uno de los jueces, no todavía con su opinión definitiva, sino con sus impresiones provisionales sobre los resultados de la audiencia y con la orientación, provisional también, que según él debe darse al fallo. ¿Por qué esta provisoriedad? Porque puede darse el caso de que un Juez, a pesar de haberse formado una impresión inicial en determinado sentido, a raíz de las audiencias, cambie esta impresión al escuchar las opiniones fundadas de alguno o algunos de sus colegas. Así, pues, la opinión emitida en un sentido por un Juez en su nota provisional, no lo obliga ni lo compromete a mantener ese punto de vista en el momento de votar el fallo. Cada nota provisional de cada magistrado es debatida en mesa redonda y puede ser objetada por los jueces restantes; se establece, así, un debate en el cual se expurga cada opinión. Ya Uds. pueden colegir cómo es de exhaustivo este procedimiento.

Terminado ese cambio de pareceres, el Presidente de la Corte suspende las deliberaciones privadas y redacta un cuestionario en el cual resume la orientación general de las quince notas y de los resultados de las discusiones que han tenido lugar por razón de la presentación de cada nota. En el cuestionario se puntualizan las cuestiones de hecho sobre las 
cuales hay, más o menos, acuerdo unánime y también las cuestiones de derecho, esto es la orientación jurídica que ha de darse al fallo, según la opinión predominante de los magistrados. Este cuestionario se somete de nuevo entonces a la "cómara secreta". Allí es discutida, cuestión por cuestión, Y, naturalmente, reformado o ampliado hasta llegar a redactarse el cuestionario final que contiene las cuestiones de hecho y las cuestiones de derecho definitivas. En este momento las opiniones de cada Juez deben quedar fijadas y la votación que se hace del cuestionario compromete la opinión de cada Juez. A partir de ese momento ya se puede decir qua hay un comienzo de fallo.

Votado el cuestionario, el Presidente nombra una Comisión de redacción formada por tres miembros de los cuales uno es obligatoriamente el Presidente, y esta Comisión es la encargada de redactar el fallo sobre la base del cuestionario aprobado. Entonces se realiza una nueva reunión de la "cámara secreta" para someterle el proyecto de fallo redactado por la Comisión y en esa nueva discusión de mesa redonda se perfecciona la redacción, o se incluye puntos omitidos por los miembros de la Comisión Redactora, o se añade nuevos argumentos o nuevos puntos que se estima de interés para perfeccionar y mejorar el fallo. Naturalmente, es frecuente que no se obtengan decisiones unánimes: hay casi siempre votos discrepantes. Lo que el Estatuto exige es un fallo de mayoría, de manera que si son quince los jueces que intervienen en un caso, besta la mayoría de ocho contra siete.

Votado el fallo se lee en audiencia pública, previa convocatoria de las partes. El fallo es inapelable: la sentencia de la Corte Internacional causa ejecutoria y allí surge una nueva deficiencia del sistema jurídico internacional, parecida a la ya señalada sobre la voluntariedad de la jurisdicción. Esta deficiencia consiste en que sólo hay una fuerza moral que obligue a la parte vencida al cumplimiento de los fallos; la Corte no tiene medios de coacción para imponer ese cumplimiento.

Entonces, cuál es el recurso indirecto al cual se ha llegado para hacer respetar los fallos de la Corte Internacional? Cuando hay algún indicio de que la parte que ha perdido el litigio no se somete al fallo o lo desconoce, la Corte Internacional trasmite este hecho al Consejo de Seguridad y este órgano político de Naciones Unidas, por propia autoridad o dando cuenta a la Asamblea, puede establecer sanciones, porque ya entonces entran en juego los resortes políticos y administrativos de la Carta que no posee la Corte, pero sí tiene la Asamblea y, sobre todo, el Consejo de Seguridad. Cuando un Estado se niega a cumplir un fallo que favorece a otro, surge entre ambos un conflicto $y$, como es función del Consejo de Seguridad evitar los conflictos $Y$ proveer las medidas políticas necesarias para prevenir su agravación, el Consejo hace uso de esas facultades y exige al Estado perdidoso que acepte la decisión de la Corte Internacional, mediante los recursos previstos en la Carta.

Esta exposición habrá dado a mis ayentes una idea aproximada de cual es la forma próctica como funciona, en la realidad viva, esa Corte Internacional que teóricamente está esquematizada en la Carta de Naciones Unidas $y$ en el Estatuto de la Corte Internacional. 
No quisiera terminar, -y me permito consultar al Señor Presidente, si dada la hora puedo extender unos diez minutos más mi disertación. (El Presidente asiente). No quisiera, digo, terminar esta exposición sin exponer dos puntos que estimo sustanciales.

Los fallos de la Corte Internacional en que se fundan? Conviene recordar que en la jurisprudencia interna o nacional, los Magistrados del mundo occidental aplican las leyes de cada país vertidas en los Códigos, según la inspiración sistemática del Derecho Romano, conforme al cual el derecho es pre-establecido en Códigos. En el mundo anglo-sajón, donde se aplica el common-law es el precedente judicial, es la jurisprudencia práctica, que se sucede de época en época, lo que sirve de horma a los jueces para seguir aplicando en los nuevos casos la tradición jurídica del Estado. Pero en el mundo internacional no existe esto, no existen leyes internacionales de carácter general y pre-establecidas que puedan normar y resolver las controversias.

Cómo se arregla la Corte para aplicar el Derecho?, qué Derecho apiica?. He aquí un problema interesante. El Estatuto de la Corte Internacional establece criterios generales que guían a los jueces para aplicar un Derecho que traduzca la justicia.

Cómo nos ayuda a los jueces el Estatuto de la Corte para orientar nuestros fallos?. He aquí sus reglas: Los fallos de la Corte Intemacional deben inspirarse, primero en el acatamiento de los tratados y convenciones internacionales. La primera norma de Derecho, clara, obligatoria para los jueces es, aplicar los tratados. Cuando hay tratados pertinentes entre los Estados litigantes, hay que buscar en la interpretación de esos tratados la solución del conflicto.

Si no hay tratado, o si las indicaciones del tratado son oscuras, qué actitud asumen los jueces?. Viene entonces un segundo criterio a prestarles ayuda, según el Estatuto de la Corte: la costumbre internacional. Cuando existe sobre una materia una reiteración de actos que a lo largo del tiempo permiten afirmar que $y a$ se ha introducido una norma habitual de Derecho entre los paises civilizados; entonces esa norma repetida y observada muchas veces hasta crear una verdadera costumbre internacional, debe ser aplicada por los jueces, ya que tal reiteración implica un consenso general de los países civilizados en el sentido de que esa norma constituye una norma de derecho. Pero puede darse un caso en que acerca del tema litigioso no exista costumbre internacional $y$ entonces el Estatuto señala una tercera norma: los principios generales del Derecho. Los jueces debemos aplicar a cada caso, a falta de las otras normas anteriores, los principios generales del Derecho, es decir aquellos dictados de orden general, muchos de ellos de sentido moral nada más, que en el consenso unánime de los pueblos civilizados y en la conciencia de la opinión pública son reputados como principios de Derecho, valga decir por ejemplo el respeto de la persona humana, el reconocimiento de la libertad individual, el concepto de autoridad, el deber de convivencia pacífica de los pueblos, etc.

Todavía viene en apoyo de los jueces un cuarto criterio que da el Estatuto. Dice éste: "se aplicará en los fallos la jurisprudencia judicial, es 
decir los precedentes judiciales, las ejecutorias. Así como el juez en la magistratura interna aplica en muchos casos el Derecho tomando en cuenta las ejecutorias de la Corte Suprema en casos análogos, de la misma manera el Juez Internacional aplica al caso que se ventila los precedentes judiciales tanto de la propia Corte Internacional como de la Corte Permanente de Justicia, busca casos similares, que los hay con frecuencia y entonces aplica esos precedentes judiciales, ese "derecho vivo" que es la jurisprudencia próctica.

Todavía hay un quinto medio por el cual los Jueces de la Corte Internacional podemos guiarnos para tratar de acertar en esta búsqueda de la justicia. Cuál es ese quinto medio?. La opinión de los tratadistas reconocidos como guias del Derecho en el mundo. Entonces, cuando no sirven de criterio suficiente ni los tratados internacionales, ni la costumbre, ni los principios generales del Derecho, ni los precedentes judiciales, entonces se acude a los libros, a las obras de Derecho de los tratadistas para buscar las fuentes del Derecho, porque indudablemente muchos de estos principios generales del Derecho que hoy son normas universales han nacido de la idea de un jurista, de la concepción de un experto. De esta manera ha querido el Estatuto crear una especie de armazón jurídico-teórica que le sirva al Juez de pauta y de norma para dictar sus fallos y para tratar de acertar en la búsqueda de la justicia.

Nótese el siguiente aspecto importante: entre esas fuentes del Derecho que los jueces debemos buscar y en las que debemos inspirarnos, hay unas que llamaríamos "pasatistas": o recogidas del pasado, y hay fuentes "futuristas" o fuentes de evolución. Por ejemplo, la costumbre internacional es una fuente que consagra el estacionatismo, porque se refiere al pasado - mantiene la tradición. La costumbre internacional se forja y vive del pasado, lo prolonga en el tiempo. Esto en muchos casos está muy bien, porque realmente el pasado es experiencia, es consagración de valores comprobados; pero la vida actual es una vida de vértigo, que evoluciona tan rápidamente que implica tantas transformaciones, y que crea tantas nuevas modalidades de costumbres, que da lugar también a nuevas, profundas $\mathrm{y}$ a veces revolucionarias formas de Derecho Entonces el criterio "pasatista" puede no ser el acertado o no ser suficiente; y será fuerza inspirarse en fuentes nuevas que interpreten mejor la época y el momento actuales. Todos sabemos que el Derecho es dinámico, no estático; el Derecho es el fruto de la transformación de la sociedad en gracia a los adelantos de la cultura, de la civilización, de la organización mundial, de los nuevos conceptos sociales que distan mucho de ser los mismos que había cntes. For consiguiente, al mismo tiempo que el juez se inspira en conceptos caducos que el pasado suministre, debe también considerar y aplicar la función dinámica del Derecho y amoldar sus fallos a las exigencias de la vida de hoy. Esto se obtiene mediante la atención de los consejos de los tratadistas, y siguiendo la evolución de los principios generales del Derecho. Valga como ejemplo la declaración de los derechos que hoy es una cosa indiscutida. Los postulados que esa declaración ha elevado a la categoría de derechos reconocidos en una ley internacional, no eran 
antes sino meras aspiraciones recortadas con frecuencia por los abusos de individuos $y$ de Gobiernos. Las dos Declaraciones representan los "derechos del hombre", a saber, atributos inherentes a la persona humana; atributos de orden moral y social que hoy se han convertido en Derecho, exigibles desde el momento que se ha promulgado la Carta de los Derechos del Hombre. Los principios generales del Derecho van evolucionando y desarrollándose, pues, a medida que evoluciona la mentalidad de la humanidad moderna; de donde se infiere que el Derecho es un concepto dinámico, volcado hacia el futuro. Cuando los jueces internacionales aplican en un fallo la noción de los derechos del hombre, del hombre no como ciudadano de una nación, no como elemento básico de la Organización de Naciones Unidas, sino porque es hombre, por su calidad de persona, están llevando el aura del nuevo Derecho a la esfera internacional. Así, los criterios jurídicos vitalistas o evolutivos vienen a equilibrar en la jurisprudencia el influjo de los criterios estáticos de la costumbre y las ejecutorias judiciales. En este sentido, por ejemplo, me parece que los países latinos tienen un margen de ventaja sobre los países sajones, porque en éstos predomina el criterio de la observancia o continuidad de la jurisprudencia anterior, de la jurisprudencia práctica establecida.

$Y$, para terminar, señores, yo quisiera citar dos casos que ha resuelto la Corte en los últimos años y en los cuales se ha creado doctrinas. Cito estos casos para que Uds. vean como la función de la Corte Internacional no es simplemente juzgadora para los fines de administrar justicia en cada caso particular, sino también una función creadora, en el sentido de que la aplicación del Derecho a un caso particular va dando lugar al surgimiento de doctrinas nuevas, que significan un aporte de perfeccionamiento jurídico en beneficio de la humanidad, porque se van estableciendo nuevos principios que no eran antes aplicados o conocidos.

Uno de los asuntos recientemente fallados por la Corte es el surgido entre los reinos asiáticos de Tailandia y Camboya sobre la posesión y propiedad del templo brahamánico de Preah-Vihear, construido en el siglo IX, que está enclavado muy cerca de la frontera de los dos países. Camboya fue un Protectorado confiado a Francia desde muchos años atrás, y Tailandia es el antiguo Reino de Siam, estado independiente. Según un Tratado del año 1904 entre Francia, como representante de Camboya, Y el Reino de Siam, hoy Tailandia, se fijó como frontera una cordillera que termina en un acantilado a pico, más allá del cual se extiende una llanura baja perteneciente a Camboya. Al lado opuesto del acantilado, sobre la meseta alta de la Cordillera, se desarrolla el país de Tailandia. Pues bien, en el Tratado de 1904 se determinaron los límites de estos dos países en el sentido de que la línea del divortium aquarum no pasaba exactamente por el borde del acantilado, sino por las altas cumbres, y, por eso, había una faja de tierras altas que pertenecía a Camboya, correspondiendo la otra vertiente a Tailandia. La demarcación de la frontera acordada se encomendó a una Comisión Mixta de militares franceses residentes en el Protectorado de Camboya y de militares siameses. Esta Comisión terminó su encargo después de tres o cuatro años de labor y presentó su informe $y$ croquis en que quedó tijado el lindero del divortium aquarum, dejando el 
órea del templo brahamánico para Camboya. Este Reino lo poseyó durante muchos años.

En 1907, tres años después del primitivo Tratado de límites, se hizo un Tratado adicional y allí se fijaron bases más detalladas para la delimitación misma de la frontera, y la Comisión, delimitadora tomó en cuenta esas bases. Anduvo el tiempo y, el año 1930, se firmó entre los dos Estados un Tratado de comercio en el que había una cláusula que ratificaba el Tratado de 1904. El año 1937 el Reino de Siam, ya convertido en Reino de Tailandia, más progresista y con mejores medios, tiene un ejército maduro con servicio aéreo-fotográfico $y$ entonces empieza a hacer sus propios planos aero-fotométricos $y$ encuentra una falla, un defecto en la demarcación del año 1904. Según ese defecto, el Templo de Preah-Vihear debería estar en territorio tailandés $\mathrm{y}$ no en territorio camboyano, porque la Comisión Mixta no habría seguido exactamente la línea del divortium aquarum. Sin embargo, el Reino de Tailandia no presenta en ese entonces reclamación $u$ observación alguna al Gobierno de Francia como Protector de Camboya, para rectificar esa frontera.

Pasan los años, viene la Guerra de 1939 y el Reino de Tailandia se alía al Japón que era enemigo de Francia; y entonces, al producirse la ocupación de Francia, el Gobierno Tailandés exige a Francia la rectificación de la frontera con Camboya y la entrega de la parte del territorio en que está comprendido el Templo de Preah-Vihear. Así, en 1941 se llega a un Tratado en que es aceptada la variación de la frontera, pero dos años después cambia el curso de la guerra, se produce la victoria francesa y a su turno Francia exige a Tailandia que se restablezcan las cosas a su primitivo estado y Tailandia firma un Tratado anulando el del año 1941 y restableciendo los límites de 1904. Después de este convenio y a pedido de Tailandia, se nombre en Washington una Comisión de conciliación para resolver equitativamente algunas alegaciones de aquel país sobre regularización de ciertas zonas limítrofes de los dos países. De esta Comisión de carácter internacional formó parte nuestro connacional el Doctor VíctorAndrés Belaúnde. Reunida la Comisión de conciliación, Tailandia formula un pliego con diversas reclamaciones entre las cuales no incluía ninguna sobre la zona del templo. La: rectificaciones demandadas versaban sobre otros territorios fronterizo; y cauces de ríos, pero no sobre reivindicación del templo. Dos años después, Tailandia ocupa militarmente el templo; $y$ entonces Camboya, erigido ya en país independiente, con extinción del protectorado francés, formula una reclamación al respecto ante Naciones Unidas $\mathrm{y}$, en vista de la ausencia de resultados, se presenta a la Corte Internacional y demanda a Tailandia por la ocupación militar del templo. Es entonces solamente cuando Tailandia alega, entre otras cosas, que hubo error material en la delimitación de 1904 a 1907 y que èn yirtud de ese error el templo debió serle adjudicado. Así, Tailandia no habría hecho otra cosa que recuperar lo suyo al ocupar militarmente el templo.

El fallo de la Corte ha favorecido a Camboya y declarado que el templo debe considerasre situado en territorio camboyano por cuanto es instrumento inamovible el Tratado del año 1904, y los procedimientos derivados de él de delimitación de la frontera, constituyen ya instrumentos y 
situaciones inamovibles. Los argumentos de hecho que apoyan esta decisión son, entre otros, que cuando se hizo el mapa de las fronteras por la Comisión mixta formada por Camboya y Tailandia, circularon los mapas en los dos países en 1908, y ellos tuvieron oportunidad de estudiar esos mapaz, sus Estados Mayores los revisaron y nadie alegó error. Las aludidas cartas fueron impresas en París, en una conocida casa editora, y el Gobierno Francés entregó solemnemente 150 ejemplares de los mapas al Ministro Plenipotenciario de Siam en París y éste lo remitió a su Cancillería en Bangkok. Esos mapas no sólo no fueron objetados por la Cancillería de Siam (Tailandia), sino que fueron distribuidos como pauta, como norma fronteriza entre los funcionarios del Estado Siamés. El argumento capital del fallo de la Corte, es que un Estado no puede objétar ni desconocer un régimen convencional o un estado de cosas que él ha aceptado reiteradamente como bueno y legal a lo largo de una serie de años. El silencio en materia internacional actúa en perjuicio de quien lo guarde. Si hay un contlicto o discrepancia grave en la relación de dos Estados, sea por infracción de un Tratado o por errores que hayan podido cometerse, todo eso debe alegarse oportunamente. Si en vez de hacerlo así, el Estado perjudicado se mantiene en silencio y acata la posesión contraria, este acatamiento implica la renuncia del ejercicio del Derecho. La estabilidad en la vida internacional es un elemento indispensable, que no debe ser alterado por obra de la voluntad tardía o extemporánea de un Estado. La buena fe se presume en favor del poseedor a quien no se le objeta su posesión; de manera que si hay silencio, si hay aceptación de ese estado de cosas por otro Estado que tiene un interés opuesto, se presume la conformidad del Estado presuntamente perjudicado.

Este es el principio que se llama de "responsabilidad por los actos propios". Cada hombre en la vida privada es responsable de sus actos; en la vida internacional cada Estado lo es también por los suyos. Si la continuidad en el tiempo revela que un Estado mantiene una política, una actitud, una conducta que hacen suponer de buena fe que acepta un estado de cosas determinado en relación con otro Estado; si el primer Estado no reclamó contra esa situación cuando pudo y debió reclamar enionces se presume que ha renunciado a cualquier posible derecho que hubiera podido invocar.

En el año 1946 en que la discusión de límites entre Thailandia y Camboya tuvo su última manifestación dentro de la Comisión de Conciliación, Thailandia pudo formular reclamación sobre el templo, y no lo hizo. Algo más, hubo un Príncipe thailandés que visitó el treintitantos la región del templo. Ese Príncipe, aparte de ser un experto en arqueología, iba investido con el cargo oficial de Ministro del Gobierno de Thailandia. Ese alto funcionario fue recibido en su visita por el Residente Francés que ejercía autoridad en el distrito al cual pertenecía el templo. Este Residente recibió al Príncipe como huésped, lo que estaba mostrando que la posesión estaba ejercida por Camboya, y que el Príncipe thailandés reconocía esa posesión puesto que aceptó las atenciones que como anfitrión le prodigó el Residente de Francia.

En resumen, la doctrina establecida en el fallo puede enunciarse 
así: El Estado cuya conducta importa una aceptación implícita y reiterada de la actitud de otro Estado sobre determinada materia, aunque esa actitud pueda ser perjudicial al primero, debe aceptar las consecuencias de su propio silencio, de su propio acatamiento a la situación de hecho creada por el otro Estado.

Otro fallo reciente de la Corte es el relacionado con el litigio promovido por Liberia y Etiopía contra la Unión Sud-Africana en cuanto Estado que ejerce la tutela del territorio del Sud-Oeste Africano, antigua colonia alemana.

El interés de este fallo estriba en que ha dejado consagrada la tesis de que los Estados por virtud de la solidaridad interestatal derivada de la comunidad de naciones, cuya expresión es la Organización de Naciones Unidas, pueden, aún sin interés personal o directo en el asunto, demandar ante la Justicia Internacional a un Estado infractor, cuando éste es inculpado de atentar contra los derechos humanos en otro Estado o Terrikorio. En ese caso. Etiopía y Liberia, dos países africanos, miembros de Naciones Unidas, sin tener un interés directo en el asunto, han demandado a la Unión Sud-Africana, antiguo miembro de la Sociedad de Naciones y, después, de Naciones Unidas, porque, en opinión de esos dos Estados, la Unión está incumpliendo las normas del Mandato que le fue conferido por la Sociedad de Naciones, para que administrara el Territorio contiguo del Sud-Oeste Africano. Los demandantes acusan a Sud-Africa de haber establecido el "apartheid" o tratamiento descriminatorio contra los habitantes del pueblo tutelado, excluyéndolos del desempeño de puestos públicos, impidiendo la difusión de la educación, restringiendo la libertad de residencia y de trabajo, etc. Liberia y Etiopía, los países alejados, se presentan velando por los fueros del país sujeto a la tutela de un tercero alegando que el Estado "tutor" no está cumpliendo sus obligaciones como tal. La respuesta del Africa del Sur ha sido en el sentido de no estar obligada a aceptar la jurisdicción de la Corte, porque Liberia y Etiopía carecen de personería para reclamar por actos que no las perjudican; y porque el Mandato instituído por la antigua Sociedad de Naciones a favor del SudOeste Africano caducó al disolverse esa Entidad mundial, ne existiendo un nuevo acuerdo de tutela entre Naciones Unidas y la Unión Sud-Africana. La tesis del fallo que ha dado la Corte, al resolver las excepciones pre. vias, es que existe personería en los demandantes, porque la institución del Mandato, que se creó en el Pacto de Versalles, en 1919, bajo el patrocinio del Presidente Wilson, dentro de la famosa teoría de las nacionalidades, tiende a favorecer a los pueblos débiles o mal desarrollados y a prepararlos para la vida independiente. El Organismo representativo de la comunidad internacional, llámese Sociedad de Naciones o Naciones Unidas, crea un vínculo de solidaridad mundial, que permite la denuncia de las violaciones de los derechos humanos a todos los Estados miembros, aunque no tengan un interés directo en el problema, si defienden un interés humano reconocido por la ley internacional.

Este es un caso más en que puede apreciarse como la doctrina jurídica va enriqueciendo con procedentes apreciables el acervo de la jurisprudencia internacional. 